\title{
Work-Life Experiences of Female Migrant Workers: A Descriptive Phenomenological Study
}

\section{Aini Inayatit,2*, Santo Imanuel Tonapa ${ }^{1,3}$, Siriluk Sithichoksakulchai ${ }^{1,4}$, and Ratna Puji Priyanti, ${ }^{1,5}$}

${ }^{1}$ College of Nursing, Kaohsiung Medical University, Kaohsiung, Taiwan

${ }^{2}$ Department of Nursing, Faculty of Health Science, Alma Ata University, Yogyakarta, Indonesia ${ }^{3}$ School of Nursing, Faculty of Medicine, Sam Ratulangi University, Manado, Indonesia

${ }^{4}$ Department of Fundamental Nursing, Faculty of Nursing, Mahidol University, Bangkok, Thailand ${ }^{5}$ Department of Medical-Surgical and Emergency Nursing, STIKES Pemkab Jombang, Jombang, Indonesia

\section{ORCID}

Aini Inayati: https://orcid.org/0000-0002-8543-8751

Corresponding Author: Aini

Inayati; email:

ainiinayati10@gmail.com

Published: 7 February 2022

Publishing services provided by

Knowledge

(c) Aini Inayati et al. This article is distributed under the terms of the Creative Commons

Attribution License, which

permits unrestricted use and redistribution provided that the original author and source are credited.

Selection and Peer-review under the responsibility of the IVCN Conference Committee.

\section{G OPEN ACCESS}

Abstract. The prior events, information, and feelings that make up someone's life or character are referred to as their experience. Some have had negative experiences, while others are glad to be able to work and contribute to the family's economic wellbeing. This paper aimed to provide a snapshot of the experience of female migrant workers in Taiwan using a descriptive phenomenological methodology. According to the findings of the study, participants' experiences included difficulty in communication, fulfilment, abuse, and adjustment to the culture. Many factors that cause migrant worker problems have emerged since the pre-placement of migrant workers in the country. That means that many factors will impact the experience of female migrant workers. Also, there are many variations of experience during working and normal life.

Keywords: migrant worker, experience

\section{Introduction}

Since the globalizing environment is built [1], all people on the planet have developed and constructed the sense and impact of globalization in order to encourage all countries to engage in the movement of different aspects of life in the fast-paced, free, and limitless world. One nation may have an impact on another, and rapid economic change may have an impact on other factors. As a result of the high demand for unskilled and low-paid labor in certain industries, this situation has affected the international migrant workers movement; this paper explicitly discusses the migrant workers movement from Indonesia [2].

Migrants are individuals who enter a foreign country to live or work. From the perspective of the host country, immigrants are those individuals who have come from 
abroad. According to the demography of migration, which has acquired an unparalleled size and diversity, there were 232 million migrants worldwide in 2013, accounting for $3 \%$ of the global population. About 20 million Southeast Asians are expected to operate outside of their home country, with the Philippines $(4,500,000)$, Indonesia $(6,000,000)$, Thailand $(500,000)$, and Vietnam $(500,000)$ being the most populous countries [3].

Labor-intensive employment and language hurdles may limit social connections and acculturation patterns for these workers. Migrant communities may be excluded due to a lack of social connection between them and their host societies, and their working conditions can have a significant impact on their health and acculturation. Migrant workers are more likely to be ostracized and exploited by their employers, to have limited access to health care, and to lack a sense of community belonging, all of which can have a negative impact on their mental and physical health [4].

Based on review article [5] migrants are frequently exposed to stressful and traumatic events, such as racial discrimination, urban violence, police abuse, forcible removal or separation from their families, incarceration or reclusion, and/or deportation, Stress and trauma have been linked to a number of mental illnesses, including posttraumatic stress disorder, major depressive disorder (MDD), psychosis, and suicide. Both pre and post migration factors contribute to the likelihood of poor mental health associated with migration. Many prevalent mental diseases put women at a higher risk than men. As a result, being a woman and a migrant may put you at a disadvantage twice over. Migrant women are more likely to be poor, have a poorer relationship to the labor market, have more childcare responsibilities, and are more likely to be victims of abuse, all of which are risk factors for mental illness [6].

Culture adaption is the process of human adaptation to novel environments. Humans must recognize that adaptation mechanisms have far-reaching implications for our understanding of population viability in the face of environmental change [7]. A migrant worker's adoption of the host country's ideas, habits, and behavior is challenge for women migrant worker.

Through two unique approaches, acculturation and ethnic relations, Intercultural has contributed to this knowledge. The first method focused on non-dominant groups' (e.g., immigrants') perspectives on how they want to live in the host society, utilizing ideas such as acculturation methods and adaptability. Using ideas such as acculturation expectations, the second approach looked at the dominant group's attitudes and behaviors toward non-dominant groups. Both perspectives, however, are one-way views of intercultural relations, ignoring the reciprocal attitudes held by non-dominant groups toward dominant groups and vice versa [8] (Inguglia \& Musso, 2015). 
Migrant laborers are visible in Taiwan, but their existence is rarely acknowledged; they are considered as the "undesirable people" on the other side of the modernity, civilization, and prosperity boundaries, which are critical components of Taiwan's selfidentity. They are barred from participating in the social programs for which they are primarily employed, from receiving permanent visas or naturalization, and from having family members join them [9](Yuniarto, 2019), When migrant laborers arrive in Taiwan, they bring with them a different culture, and their presence is also denied.

Taiwanese culture consequently 'stigmatizes' or 'makes invisible' these 'new taikers.' In terms of education, Indonesian factory workers, fishermen, and careers are still unqualified as compared to Filipino, Thai, or Vietnamese migrants. Filipino workers, for example, must complete their credentials, and Vietnamese workers must undergo training before being allowed to work in Taiwan. Because Thai migrants are already designated as industrial or construction employees, they adapt more quickly. Meanwhile, according to this survey, the majority of Indonesian workers have only completed elementary school; they learn by doing and have minimal awareness of work norms and circumstances [10] (Tierney \& Faifua, 2008).

Based on background and review article, in the future this article wants to know about Work-life experiences of female Indonesian migrant workers in Taiwan.

\section{Methods}

\subsection{Study design and participant}

When the purpose of research is to describe a phenomenon based on a person's perception of their experience in a particular scenario, a qualitative study is acceptable based on [11] (Baxter \& Jack, 2015). In this study qualitative study takes a qualitative phenomenology approach, in which participants narrate their daily lives [12](Ezzy, 2000). In the depth interview we use open question about their experience during their work in Taiwan. The purpose of this study was to examine the work-life experiences of female Indonesian migrant workers, languages and customs, a qualitative approach was the most appropriate choice to explain how life at workplace is more detailed and in-depth. Data collection In this study, researchers conducted this research by collecting 15 participant data on respondents, but those who met the requirements were 10 participants based on inclusion criteria Indonesian citizens who work in Taiwan, want to be participants and can speak Indonesian fluently. 


\subsection{Data processing and analysis}

The researcher coded the transcripts in the order in which the interviews were done, in batches of four at a time, allowing her to reflect on and change the interview questions as theories emerged from the data. The researcher used coding to better comprehend the participants' viewpoints and analyze their combined experiences. During the study process, codes were constructed based on the data for the purposes of data analysis [13](Cope, 2010). Coding was conducted both manually and using computer assisted qualitative data analysis software.

The process of analyzing, reanalyzing, and comparing new data to existing data is known as constant comparison [14,15]. As each phase of coding began, it was important to continue reviewing the data in previous phases so that connections were constantly being made until saturation occurred. Coding terminology used for this article was adopted from (Williams, 2019) [16] who termed the three phases of coding as open, selective, and axial there is:

1. Open coding the initial level of coding is open coding. The researcher uses open coding to find separate concepts and themes for categorisation. The first level of data organization is accomplished by establishing broad subject domains for data collection. Open coding is the initial step, and it seeks to express facts and phenomena as concepts. Classifying expressions (single words, short sequences of words) into units of meaning in order to attach annotations and "concepts". This method of coding helped the researcher focus in-depth on every interview.

2. Axial coding is the second level of coding is axial coding. Axial coding, in contrast to open coding, which focuses on uncovering emergent themes, refines, aligns, and categorizes the concepts further. After completing open coding and transitioning to axial coding, the obtained data can be sorted, filtered, and categorized in order to create distinct theme groupings in preparation for selective coding [16] (Williams, 2019). In this study use axial coding for refines, aligns, categorizes, and grouping.

3. Selective Coding The third level of coding is selective coding. It allows the researcher to choose and combine categories of ordered data from axial coding into coherent and meaningful expressions. Selective coding extends axial coding to a higher degree of abstraction [via] efforts that result in the elaboration or formulation of the case's story [16](Williams, 2019). This of data framing allows the researcher to strive toward topic specificity and, as a result, theory development. Thematic refinement can reveal degrees of causation or predictability, allowing 
the researcher to uncover sets of conditions in which particular replies will elicit responses that show particular circumstances receive distinct and distinctive reactions. After selective coding is completed, the researcher can move on to establishing theory and, eventually, constructing meaning.

4. Computer assisted qualitative data analysis software, ATLAS.ti, was used to aid in the data management and analysis process. The software was also used to query key words for comparison with manually coded categories and themes [17]. Software was useful as a repository and for sorting through data [17].

5. The trustworthiness and validity based on [18] noted that credibility, transferability, dependability, and confirmability are important in establishing trustworthiness. One of the ways to ensure credibility and transferability is to ensure that those interviewed have the experience to discuss the phenomenon the researcher seeks to explore [18].

\subsection{Ethic}

The researcher ensured ethics remained a top priority throughout the study. Following the methods the informed consent form, read to each participant prior to the interview. Ethical will register in University to review this article.

\section{Results}

\subsection{Socio-Demographic Characteristics of Participants}

Most participan migrant workers were married and graduated from senior high school. One of my participants had been staying in Taiwan to continuing their education from elementary school to junior high school. Most is having experience working here mostly two years.

\subsection{Descriptive Main category and subcategories of interviews with participants}

\subsubsection{Difficulty in communication}

The result from interview female migrant worker has both experience a good and bad during them in here. The main category experience of difficulty in communication 
TABLE 1: Socio-Demographic Characteristics of Participants

\begin{tabular}{|c|c|c|c|c|}
\hline No & Age & Gender & Education level & Working experince in Taiwan \\
\hline P-1 & 32 & $\mathrm{~F}$ & Junior high school & $\begin{array}{l}14 \text { months first contrac } 5 \\
\text { month second contrac }\end{array}$ \\
\hline P-2 & 31 & $\mathrm{~F}$ & Senior high school & 2 years \\
\hline P-3 & 35 & $\mathrm{~F}$ & Junior high school & 18 month \\
\hline$P-4$ & 42 & $\mathrm{~F}$ & $\begin{array}{l}\text { elementary } \\
\text { School }\end{array}$ & 4 years \\
\hline P-5 & 30 & $\mathrm{~F}$ & Senior high school & 5 years \\
\hline P-6 & 31 & $\mathrm{~F}$ & Senior high school & 3 years \\
\hline P-7 & 28 & $\mathrm{~F}$ & Junior high school & 3 years \\
\hline P-8 & 22 & $\mathrm{~F}$ & $\begin{array}{l}\text { elementary } \\
\text { School }\end{array}$ & 4 years \\
\hline P-9 & 35 & $\mathrm{~F}$ & Junior high school & 2 years \\
\hline P-10 & 36 & $\mathrm{~F}$ & Junior high school & 3 years \\
\hline
\end{tabular}

TABLE 2: Descriptive Main category and subcategories of interviews with participants

\begin{tabular}{l|l}
$\begin{array}{l}\text { Main category } \\
\text { Difficulty in communication }\end{array}$ & $\begin{array}{l}\text { Subcategory } \\
\text { language barrier } \\
\text { Restricted for communicating }\end{array}$ \\
\hline Fulfilment & Financial stability of the family \\
\hline Abused & Physical \\
\hline Adjustment to the culture & Psychological \\
\hline
\end{tabular}

on another word is known as language barrier to communication. The most common communication hurdles are language obstacles, which lead to misunderstandings and misinterpretations. Mostly migrant worker in the first time came said difficulty communication in mandarin language.

\section{Language barrier}

Most participant state in the first came to here can't interaction well the instruction from employer because of language. Some participant said in the agency actually have basic training for language before we came here but just for basic. And we learn is different that people here used in daily conversation. This state support from participant:

"Previously I worked here for 14 months already. At that time, I didn't yet know how to speak [mandarin language]. even though I came here twice I'm Also, right now I still learn mandarin" (participant number1). 
"It was the first time here I can't interact with people or employer because of language [Mandarin]" (Participant number 3)

\subsubsection{Fulfilment}

Other participant mention about fulfilment came here because need support their family financial to getting better life or for treatment their parents. Some also mention want back after she have some house for their children, and give their children money and support stability financial.

1. Financial stability of the family

This state from participant that mention about financial stability for their family.

"I come here to help the family economy; my father needs treatment so he needs a money to get better treatment, also he can't heavy work so that's mean he need rest and only a little can be done in their work" (P.2, P.7)

"If everything is reached, the house is finished, I want to go home. I just want my family economy Stabil, can give my children money build a house and at least I can pay for my child's school, in this way my children can get a good education, and fulfilled all their needs" (P.3, P.1)

\subsubsection{Abused}

Participant also share their experience about struggling to be patient and keep working here event they get some abuse from their employer.

Physical

Some participant they get same physical abuse during working time, they mention:

"At that time, I want rest because it's late at night, he tells me to do clean a bottle and same glass, at that time I forgot to bring to here because their wife also tells me to do something, then he spoke loudly and he said: hey dog, you forget it and then he hit my chest five time, I feel it hurts and just crying" (P.4and P.5)

In the first employer I was always blamed and one time he hit my body until it's bruised, because at that time I taking care the idiot kid. He hyperactive I can't control 
it, I was new at that time, I don't have any experience taking care of idiot kids, so I didn't know what should I do, then I just keep silent because I afraid" (P.3and P.6)

\section{Psychological}

Not only physical but some mention there is psychological abuse. because at work there is a lot of pressure and demands from employers, however he thinks about it. On the other hand, if this migrant worker does not live with his employer, he is calmer and gets a lot of freedom to do what he likes

"in the first employer he said I was lazy and could not work, but actually at that time I invite her father to do sports, walks in the park but he doesn't want to do it, then he was cursed, I try to explain it but he didn't accept it, then I just silent because I don't have any power to argue" (P. 3, P.8)

"I work like robot, actually I just want to work, I will do all the work as long as I don't be rude, then every time talking to me means talking a dog and being bullied in that's home, mentally l'm tired to keep silent and just do it, so I am planning to change employers. but he said don't leave just work here my father no one takes care if you move" (P.4, P.9).

\subsubsection{Adjustment to the culture}

Some interesting came if we are mention about culture, Individuals naturally bring their own background and life experience with them when they leave their own culture and migrate to another. People's reactions to the new culture, as well as their ability to adapt to it, are frequently a mirror of their own upbringing and expectations.

Grateful for the situation

Participant mention about they are happy to be back and able to work here even though some have to adjust to the culture here, this is still very helpful for them in providing jobs when it is difficult to find work with a low level of education.

"I am grateful to be able to come here again to work now everyone is grateful even though it is far from family, but their intention is to help the family economy" (P.1, P.10)

"At that firs time in this employer he doesn't allow me to wear hijab in outside, but thankfully right now my employer understands the habit of wearing the hijab, and it is 
an obligation of my religion. Then right now I can wear the hijab when In outside, and I am very happy that my employer accepts this different culture and religion" (P.3)

1. Spiritual need

"Because of my work sometime I don't be able to do pray 5 time, I miss being able to pray 5 times a day, reciting the Al-Quran and do other religious activities like in my home town" (P. 2, P.6)

\section{Discussion}

Described overseas migrant workers' working conditions differ greatly from country to nation and industry to industry. For most destination countries, Indonesian migrant workers in formal sector employment have some access to standard labor relations processes. Even so, basic worker rights are not always respected. In some places, such as South Korea and Hong Kong, migrant workers are allowed to form unions. Moreover, while migrant workers in some countries, such as Malaysia, are not prohibited from joining a union under industrial relations law, they are prohibited from doing so under the terms of their work visas. Furthermore, the company or the agency may keep workers' passports, and work visas are frequently attached to a certain firm. This means that if the migrant worker's working conditions aren't suitable, he or she won't be able to simply switch jobs. They may also be unable to return home, as most employment contracts indicate that if the contract is broken, the migrant worker is responsible for all return costs.

The article from[19] (Ford, 2016) said that's The situation is much more complicated for the enormous number of Indonesian women who work as domestic servants in other countries. Although there is a risk of abuse in any job where the employee does not have full citizenship rights, foreign domestic workers confront a unique set of issues due to the location and nature of their work. Domestic employees are denied protection under labor laws since their employment takes place in the private sphere (and hence outside the scope of most industrial relations systems).

Many cases of female migrant workers, especially those who are subjected to both verbal and physical abuse, are unreported because they are women. According to a Reuters story published on Thursday, September 19, 2013, a survey of more than 3,000 migrant women working in Hong Kong found that 58 percent had been verbally 
abused, 18 percent had been physically harassed, and 6\% had experienced sexual harassment. Qualitative evidence from the Serikat Buruh Migran Indonesia also supports these conclusions [20](Rahayu, 2018).

Although female migrants/potential female migrant workers have a low educational level, information in the form of written material will have a limited influence on empowering women. according to studies [20] (Rahayu, 2018) conducted in three Indonesian female migrant worker origin locations. Female migrants/potential female migrant workers are poorly informed on all aspects of the migration process or working conditions in other countries, their primary sources of information are a recruitment agency (brokers) that they are familiar with. This puts migrants and potential migrants in a vulnerable position, and they are more likely to be exploited as a result. Because the recruiting process takes lengthier, the involvement of agents/brokers (sponsor/calo are the local names in Indonesia) is another key element that puts female migrants/potential female migrant workers at risk of exploitation and prejudice.

\section{Conclusion and limitation}

Some factors that cause migrant worker problems, in general, have emerged since the pre-placement of migrant workers in the country, with the non-fulfillment of standards in the process of preparing and debriefing BMI by PPTKIS, however BMI does not have the capacity to work in accordance with the demands of the job, in addition to a lack of understanding and knowledge. some workers say working here really helps them to have stability in economic sector. so we can't judge all employers are not kind to migrant workers. This has even become an evaluation material for the government to improve the quality of the workers here.

Limitation this article is the number of samples is small, resulting in this research overview narrow it's necessary to add samples, then that they can fully see the contents of this study.

\section{References}

[1] Lewis J. Cultural studies - The basics. Sage; 2002.

[2] Marsiglia FF, Booth JM. Cultural adaptation of interventions in real practice settings. Research on social work practice. 2015;25:423-432.

[3] Cheng H-I. On migrant workers' social status in Taiwan: A critical analysis of mainstream news discourse. International Journal of Communication. 2016;10:20. 
[4] Aung TNN, Shirayama Y, Moolphate S, et al. Acculturation and its effects on health risk behaviors among Myanmar migrant workers: A cross-sectional survey in Chiang Mai, Northern Thailand. International Journal of Environmental Research and Public Health. 2020;17:5108.

[5] Bustamante LHU, Cerqueira RO, Leclerc E, et al. Stress, trauma, and posttraumatic stress disorder in migrants: A comprehensive review. Brazilian Journal Psychiatry. 2017;40:220-225.

[6] Straiton M, Corbett K, Hollander A-C, et al. Outpatient mental healthcare service use among women with migrant background in Norway: A national register study. BMC Health Service Research. 2019;19:1-11.

[7] Fogarty L, Kandler A. The fundamentals of cultural adaptation: Implications for human adaptation. Scientific reports. 2020;10:1-11.

[8] Inguglia C, Musso P. Intercultural profiles and adaptation among immigrant and autochthonous adolescents. Europe's journal of psychology. 2015;11:79.

[9] Yuniarto PR. Migrant workers empowerment through vocational education and community-based learning: A study case of indonesian in Taiwan. Journal of Indonesian Social Sciences and Humanities. 2019;9:113-130.

[10] Tierney R. Inter-ethnic and labour-community coalitions in class struggle in Taiwan since the advent of temporary immigration. Journal of Organizational Change Management.

[11] Pfaff KA, Baxter PE, Jack SM, et al. Exploring new graduate nurse confidence in interprofessional collaboration: A mixed methods study. International journal of nursing studies. 2014;51:1142-1152.

[12] Ezzy D. Qualitative analysis. Routledge; 2013.

[13] Cope M. Coding transcripts and diaries 27. Key methods Geogr. 440.

[14] Mills J, Birks M. Qualitative methodology: A practical guide. Sage; 2014.

[15] Urquhart C. Grounded theory for qualitative research: A practical guide. Sage; 2012.

[16] Williams M, Moser T. The art of coding and thematic exploration in qualitative research. International Management Review. 2019;15:45-55.

[17] Bryant A, Charmaz K. Grounded theory in historical perspective: An epistemological account. Handb Grounded Theory. 2010:31-57.

[18] Lincoln YS, Guba EG. Naturalistic inquiry. Sage; 1985.

[19] Ford M. Migrant worker organizing in Indonesia. Migration Journal. 2006;15:313-334. 
[20] Rahayu N. Indonesian migrant worker policies and the vulnerability of women migrant workers to becoming trafficking victims: An overview of recent legislation. JSEAHR. 2017;1:159. 